It may be remarked that, in spite of a long and varied series of diffusion experiments, we have been unable to prepare magnesium hydroxide in good crystals, presumably because the actual rate of diffusion was still not small enough in view of the limiting saturation of this substance. Similar attempts with silicates resulted in the separation of colloidal material only; this may be due to hydrolysis, or to the insolubility of the silicate, or to both of these factors. The only possibility of increasing the saturation limit in this case would seem to be increase of temperature; and it is very doubtful if this would avail much, since the indications are that silicates are still very sparingly soluble in water even at temperatures of $360^{\circ}$ or higher. A few trials made at $200^{\circ}$ in a small autoclave were unsuccessful; indeed the experimental difficulties in the way of securing sufficiently slow mixing at temperatures above $100^{\circ}$ are very great, so that we abandoned attempts to prepare crystalline silicates in this way.

Nevertheless, it is probable that, by means of diffusion experiments as described above, one may prepare good crystals of many sparingly soluble substances, which otherwise cannot readily be obtained except as very fine powder, usually more or less contaminated with occluded material. The slowly formed crystals obtained in this way are practically free from impurity and hence constitute first-rate material with which to undertake physico-chemical determinations, such as measurements of solubility. The use of this type of material for such purposes would doubtless yield quite definite and reproducible results which would, with advantage, replace some of the present uncertain data.

GEOPHXSICAL LABORATORY,

CARNegie Institution OF WAshington,

October, 1913.

\title{
A NEW METHOD FOR THE PREPARATION OF COLLOIDAL FERRIC HYDROXIDE.
}

By Thzodore CoHEN.

Recived November 3, 1913.

Many of the methods already in use for the preparation of soluble ferric hydroxide are based upon the hydrolysis of a ferric salt. The soluble ferric hydroxide thus formed is held intact without any appreciable evidence of the settling of the solid phase, after standing for some time. A typical reaction of this kind takes place when a molar ferric chloride solution is neutralized with a molar ammonium carbonate solution. If the liquid thus obtained is filtered and then dialyzed, ferric hydroxide will be obtained in the colloidal state, brought about through the hydrolysis of the ferric salt, according to the main reaction: ${ }^{1}$

$$
\mathrm{FeCl}_{3}+{ }_{3} \mathrm{HOH}=\mathrm{Fe}(\mathrm{OH})_{3}+{ }_{3} \mathrm{HCl} \text {. }
$$

1 A. A. Noyes, This Journal, 27, 94 (1905). 
The writer claims another method for preparing colloidal ferric hydroxide, due to the hydrolysis of an iron salt, ferric nitrate, which hydrolysis takes place in a nitric acid solution, containing free reacting copper. A careful research through the available chemical literature gave no account of the preparation of colloidal ferric hydroxide according to the method which is described below.

While working with a copper sulfate solution, in which was immersed an iron nail, dilute nitric acid was accidentally added in excess. A violent reaction took place, brownish fumes were evolved (liberation of $\mathrm{N}_{2} \mathrm{O}_{4}$, nitrogen peroxide) and at the end of the reaction, a reddish yellow mixture was obtained. This was filtered several times, the liquid passing through the filter paper unchanged, and viewed by transmitted and reflected light. In the former case, the color was deep red, but in the latter, a distinct reddish yellow opalescence (probable presence of a colloid) could be readily seen. A drop of concentrated sulfuric acid was added, when a red-brown gelatinous precipitate immediately appeared. This precipitate was found, upon analysis, to be ferric hydroxide. Another portion of the liquid was placed in a U-tube and an electric current sent in. A red gelatinous mass appeared on the cathode and when analyzed was also found to be ferric hydroxide. Concluding that a colloid was probably present in solution, and that the presence of copper influenced its formation, the following experiments were carried out:

(r) Three grams of iron (nails) were placed into ro cc. concentrated nitric acid in a large test tube. No reaction took place. This would be expected, since concentrated nitric acid renders the iron passive.

(2) Three grams of iron (nails) were placed in Io cc. concentrated nitric acid in an Erlenmeyer flask and a small piece of sheet copper was added at the same time. No action occurred but when diluted with a little water, immediate violent action took place. At the conclusion of the reaction, a dark red liquid was obtained which was filtered and dialyzed to remove electrolytes. (a) A ro cc. portion was treated with concentrated sulfuric acid, when immediate coagulation took place. (b) Another portion was placed in a $\mathrm{U}$-tube and a current of r ro volts passed in. A gelatinous red precipitate collected on the cathode. (c) Still another portion was treated with electrolytes of varying concentration and in each case coagulation took place, with increased speed as the concentration of the electrolytes increased. Electrolytes having anions of high valence were still more effective in producing coagulation than those having low valence anions. The facts that sulfuric acid, other electro$1 y$ tes and the electric current precipitated ferric hydroxide, verify its original colloidal nature. The collection of the precipitate around the cathode proves the colloid to have a positive charge. Such is known to be the case with true colloids of ferric hydroxide. 
(3) Three grams of iron (nails) were placed in dilute nitric acid, specific gravity 1.20, and allowed to react. A slight brownish solution was obtained. The addition of sulfuric acid failed to produce coagulation; there was simply a change in color to pale green, as would be expected of ferric salts when they are treated with sulfuric acid. At times, in the above case where copper was absent, a slight precipitate appeared upon the addition of sulfuric acid. This was probably due to the slight hydrolysis of the ferric salt, giving soluble ferric hydroxide, which would be precipitated by the addition of sulfuric acid.

Another set of experiments was carried out with iron as filings, containing copper as an impurity. Colloidal ferric hydroxide was also obtained.

(I) Two grams of iron (filings) were added to $5 \mathrm{cc}$. concentrated nitric acid in an Erlenmeyer flask. No action took place. Water was added from a buret until the reaction started. A brownish red, curdy, gelatinous mass was left, which went into solution on the addition of water. This was filtered and dialyzed, when a yellow-brown liquid was obtained, which showed distinct opalescence.

(2) Three grams of iron (filings) were placed in $5 \mathrm{cc}$. concentrated nitric acid and then diluted. Reaction began and the resulting liquid was filtered and dialyzed. Opalescence was clearly visible.

(3) Three grams of iron (filings) were added to ro cc. concentrated nitric acid and diluted. The mixture was filtered and dialyzed when a deep, ruby- or blood-red liquid was obtained. In this case, the color was deeper red than in the two previous experiments. The acid when diluted in each case had a specific gravity about 1.20. Each solution showed distinct opalescence and a drop of sulfuric acid or the electric current caused coagulation with the separation of ferric hydroxide. These tests again verify the colloidal nature of the ferric hydroxide. Mixtures thus prepared have remained since April without the least evidence of the settling of the solid phase, ferric hydroxide.

However, when I gram of iron filings was added to concentrated nitric acid, diluted, and then filtered at the end of the reaction, a clear yellowbrown filtrate was obtained; the addition of sulfuric acid failed to produce any coagulation. This may perhaps be due to the excess of nitric acid in the solution, which would tend to drive back the hydrolysis completely, in the case of the nitrate. ${ }^{1}$

$$
\mathrm{Fe}\left(\mathrm{NO}_{3}\right)_{3}+{ }_{3} \mathrm{H}_{2} \mathrm{O} \leftrightarrows \mathrm{Fe}(\mathrm{OH})_{3}+{ }_{3} \mathrm{HNO}_{3} .
$$

Having obtained a colloid with iron filings which were known to contain copper, iron, reduced by hydrogen, was placed into dilute nitric acid. This solution gave no test for colloidal ferric hydroxide; but when a similar portion was placed into concentrated nitric acid, containing a small piece of copper, and then diluted, the colloidal ferric hydroxide which was pro-

${ }^{1}$ A. Smith, "Inorganic Chemistry," Ig12, p. 755. 
duced was precipitated upon the addition of a drop or two of concentrated stilfuric acid.

Since iron, copper, water and nitric acid are the chief constituents, the main reaction which produces the colloid could be expressed by an equation,

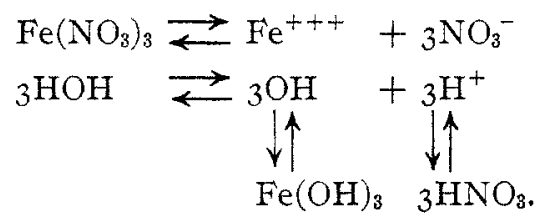

The formation of soluble ferric hydroxide, brought about by the hydrolysis of the ferric nitrate in the solution, must have been favored in some manner, by the presence of the copper.

As shown by the second equation, the presence of nitric acid would drive back the hydrolysis of the ferric salt completely. Reasoning upon this fact led to the conclusion that the ferric hydroxide formed as a result of hydrolysis would remain as such, if the effect of the nitric acid could be destroyed. With this in view the following experiments were carried out:

(1) A concentrated solution of ferric nitrate was boiled for a considerable time, when the yellow-red original color of the solution became deep red. Upon cooling, however, the deep red returned to its original color, and sulfuric acid gave no trace of colloidal formation. This would be expected, since the nitric acid formed would reverse the reaction, as already indicated.

(2) Another boiling solution of ferric nitrate was treated with copper filings and a deep blood-red solution was obtained. This was filtered and allowed to cool but the deep blood-red color still remained. The addition of sulfuric acid gave a heavy precipitate of ferric hydroxide, and further tests verified the presence of cupric nitrate in the solution. Copper having combined with the nitric acid, the ferric nitrate could then hydrolyze. Cooling would have no effect since the reversing power of the acid was destroyed. Sheet copper was similarly treated with the same result, except that the blood-red color was tinged with a brownish opalescence, due, no doubt, to the incomplete removal of the nitric acid, since finely divided copper would be more effective in reacting with the acid.

The next question that arose, would other metals have the same effect? To answer this, the following experiments were necessary:

(3) Solutions of ferric nitrate were boiled with an iron nail, reduced iron, iron filings (containing copper), mossy zinc and zinc dust. In each case filtration retained no precipitate on the filter paper. Beautiful red solutions were obtained when the metal was in a finely divided condition and tinged with a brown opalescence when otherwise. Each solution gave 
ferric hydroxide when treated with sulfuric acid or the electric current, and obeyed the characteristic tests for colloids. Dialysis gave the crystalloids which were analyzed and found to be, in each case, the nitrate of the metal. In fact the colloids formed by starting directly with ferric nitrate were deeper in color than when nitric acid was employed to first form the nitrate.

The conclusions arrived at are: that hydrolysis was temporarily possible only at the boiling temperature when nitric acid was present in excess; that the addition of a metal combining with the nitric acid formed as a product of the reaction, when the nitrate was used; and with the excess acid when ferric nitrate was formed in the presence of the free acid, favored hydrolysis by destroying the effect of the nitric acid present; that the most favorable condition under which colloidal ferric hydroxide is formed would be one in which the nitric acid was completely removed; and that the finer the state of division of the metal which is used to remove the nitric acid, the deeper red the colloidal solution, since the completeness of the removal of the nitric acid would favor the degree of hydrolysis of the ferric nitrate to colloidal ferric hydroxide.

Experiments are also being carried out to determine whether the nitrates or other salts of the metals would behave similarly, or whether the metals in the electromotive series could be advantageously employed, as was the case with iron and copper salts, to bring about colloidal reactions by precipitating a metal from its solution by one that is more electropositive.

Commercial, High School, Chemical Laboratory, BROOKLYN, N. Y.

\section{THE REDUCTION OF HYDRONITRIC ACID. II. THE STRUC- TURES OF THE TRINITRIDE RADICLE. \\ BY J. W. TURRENTINE. \\ Received November 12, 1913.}

It is the purpose of this paper to show that Fisher's interpretation of the reaction yielding diazobenzeneimide, on which is based the conception of the cycloid structure of the trinitride radicle, is erroneous, since that reaction in all essentials is an oxidation of hydrazine; that in no instance where the oxidation of hydrazine has been studied has a reaction been observed analogous to the one in this case proposed by Fisher. It will be maintained that the interpretation of a reaction which is open to such doubt can not be taken as a sufficient basis for the structure of a compound resulting from this reaction. A new open-chain structure will be propased for the trinitride radicle and evidence adduced from new reactions observed in a study of the reduction of hydronitric acid and its salts will be brought to bear in support of that structure. 